Blok, C. de, Meijboom, B., Luijkx, K., Schols, J. The human dimension of modular care provision: opportunities for personalization and customization. International Journal of Production Economics: 2013, 142(1), 16-26

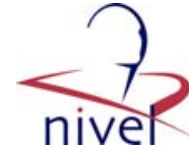

\begin{tabular}{|l|l|}
\hline $\begin{array}{l}\text { Postprint } \\
\text { Version }\end{array}$ & 1.0 \\
\hline Journal website & http://www.sciencedirect.com/science/article/pii/S0925527312001818 \\
\hline Pubmed link & \\
\hline DOI & $10.1016 /$ j.j.jpe.2012.05.006 \\
\hline
\end{tabular}

This is a NIVEL certified Post Print, more info at http://www.nivel.eu

\title{
The human dimension of modular care provision: Opportunities for personalization and customization
}

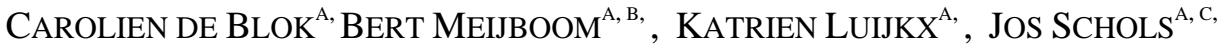 \\ a Department of Tranzo, Tilburg University, the Netherlands \\ ${ }^{\mathrm{b}}$ Department of Organization and Strategy, Tilburg University, the Netherlands \\ ${ }^{c}$ Department of General Practice, Maastricht University, the Netherlands
}

\section{ABstract}

Various behavioral issues are at stake in the health care sector, for example, the current strong plea for more demand-based care provision as opposed to traditional supply-driven approaches. Healthcare organizations are increasingly in need of systems and approaches that allow them to be more responsive to the needs and desires of their clients. To cope with heterogeneous and multiple demands, the application of modularity is increasingly proposed in care and services. In this paper the purpose is to study how interpersonal behavior responsive to client needs and values can be accommodated in modular care provision. Drawing on relevant literature from various service-related disciplines, we develop insight into how customization and personalization are simultaneously practiced by means of case research in the context of long-term care for elder people.

Our empirics indicate that in care for elder people, personalization complements customization in adapting supply to demand. Customization is used to better match the needs of an individual customer in terms of the content of the service. Personalization is also used for this purpose, however, by adapting the way in which the service is provided. Moreover, the practice of personalization effectuates customization over time. The paper shows the importance of human behavior in the application of modularity in long term care for elder people. Approaching the issue of adaptation through the lens of modularity offers care providers insight into how customization and personalization are related. These insights can be used for the design of care delivery systems that enable comprehensive adaptation of supply to heterogeneous customer demands over time. 
Blok, C. de, Meijboom, B., Luijkx, K., Schols, J. The human dimension of modular care provision: opportunities for personalization and customization. International Journal of Production Economics: 2013, 142(1), 16-26

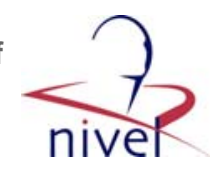

\section{[FIGURE 1]}

\section{INTRODUCTION}

Modularity enables service organizations to provide customization efficiently and be responsive towards needs of individual service consumers (e.g., Meyer and DeTore, 2001, Miozzo and Grimshaw, 2005, Pekkarinen and Ulkuniemi, 2008 and Sundbo, 1997). In health care, first steps towards the application of modularity have been made (Bohmer, 2005, Chorpita et al., 2005, De Blok et al., 2010, Langlois and Savage, 2001 and Meyer et al., 2007), however, as in other service settings, mainly from a rather technical point of view, thereby largely reflecting its manufacturing origin. However, the success of any operations management (OM) concept, tool or technique, and the accuracy of its theories, relies heavily on our understanding of human behavior in the context in which it is applied (Bendoly et al., 2006). In health service contexts, where services are created in close interaction between service provider and health care customer, the potential influence of human and behavioral aspects on the application of an OM concept is large. Realistic human behavior, therefore, needs to be incorporated into the concept of modularity to gain insight into its actual potential. Thus, rather than developing another technical application, our purpose is to study how interpersonal behavior responsive to client needs and values can be accommodated in modular care provision.

More specifically, the provision of care involves extensive and intimate customer contact (Jaakkola and Halinen, 2006 and Verma, 2000). As the service is mainly

targeted at the receiver's body or mind, healthcare services are prime examples of customers working together with the provider in co-creating value (Lanseng and Andreassen, 2007 and Vargo and Lusch, 2004). Value co-creation, thus, implies that customization of the service package offered can be highly influenced by human or behavioral aspects. Besides the adaptation of technical contents of care provision, a personal touch to and on-going relationships in care delivery are required (Bosman et al., 2008, Sofaer and Firminger, 2005 and Ware et al., 2003). This is especially important when care clients are in a relatively frail position which might cause a lack of trust and high degree of perceived uncertainty during care delivery (Moliner, 2009).

To integrate modularity research focusing on customization of the service offering with behavioral concepts that incorporate human interaction, we turn to the concept of personalization. This concept focuses on how service professionals interact with customers and tune interpersonal interaction to customer needs. Research and insights concerning modularity and customization have been largely developed independently from research concerning personalization aspects. To incorporate realistic human behavior as one critical component into the concept of modularity, thereby integrating customization and personalization in care and service delivery, these two literature streams should be brought together and knowledge should be created on the actual contribution of personalization in the adaptation and delivery of customized care offerings. This paper therefore addresses the following research question: How does personalization contribute to the provision of customized modular long-term care? We first provide an overview of existing knowledge on customization and personalization in relation to modularity and provide an overview of how both concepts work towards tuning supply to demand. To further examine 
Blok, C. de, Meijboom, B., Luijkx, K., Schols, J. The human dimension of modular care provision: opportunities for personalization and customization. International Journal of Production Economics: 2013, 142(1), 16-26

and refine this overview in the context of care, we conducted case research in organizations that provide care and services to elder people living independently. These organizations face high diversity in demand and high intensity of customer interaction. The case study findings are first described and then discussed from a customization and personalization perspective. From our research, it follows that personalization serves more goals than have been identified in literature so far; it complements as well as effectuates customization. Conclusions, including consideration of the implications of the research, complete the paper.

\section{THEORY}

Customization is defined as the configuration of products and services that meet customers' individual needs (Pine, 1993). Customization research has been developed in the fields of product design and operations management to develop ways in which goods and services can be adapted to individual standards. Modularity has been widely identified as a means to bring about cost-effective customization (e.g., Duray et al., 2000, Hsuan and Skjøtt-Larsen, 2004 and Pine, 1993).

Personalization is defined as the adaptation of employee interpersonal behavior such that it suits a particular customer's preferences (Gwinner et al., 2005).

Personalization stems mainly from service marketing and management and has been developed in these fields over the years in order to individualize and fine tune the way in which services are delivered. Both concepts have found their way into the health care sector in order to accommodate individual demands. In the next sections, we will introduce the concepts of customization and personalization, including their what's, why's and how's. We will discuss their application in health care and argue why the concepts should be integrated in order to achieve care delivery that is tuned to individual client's and patient's needs.

\subsection{Modularity to achieve customization}

Modularization, in general, is an approach to organize complexity in an efficient manner (Baldwin and Clark, 1997) and from a systems point of view refers to the degree to which a system's components can be separated and recombined (Schilling, 2000). In the field of operations management, modularity is understood mainly from the perspective of component combinability; different product configurations can be obtained by mixing and matching components taken from a given set by means of standardized interfaces (Salvador, 2007).

To achieve customization and address heterogeneous customer demands, organizations develop largely standardized components and modules that can be employed efficiently in a variety of configurations (Salvador, 2007). To the extent that different customers require different outputs, product variants may differ in one or more modules, the rest of the product being unaltered. As such, not all components need to be subject to change to address market fragmentation (Salvador, 2007).

To achieve customization, modularity has been applied both in goods (e.g., Hsuan and Skjøtt-Larsen, 2004, Muffato, 1999 and Starr, 1965) and in services (e.g., Meyer 
Blok, C. de, Meijboom, B., Luijkx, K., Schols, J. The human dimension of modular care provision: opportunities for personalization and customization. International Journal of Production Economics: 2013, 142(1), 16-26

and DeTore, 2001 and Pekkarinen and Ulkuniemi, 2008). One characteristic that distinguishes services from goods, and thereby influences the application of modularity, is the role of human behavior (Meyer and DeTore, 2001 and Voss and Hsuan, 2009). Services come into existence in close interaction between producers and customers (e.g., Edvardsson et al., 2005 and Sampson and Froehle, 2006) and during these encounters service employees perform activities that modify the service offering in accordance with customers' needs and requirements (e.g., Gwinner et al., 2005). In modular services, thus, customization is often achieved by service workers who put together and configure the necessary components for each client (Meyer and DeTore, 2001 and Voss and Hsuan, 2009).

In literature on service modularity, two ways for achieving customization of the service package offered can be recognized. First, variety can be obtained by combining menu components, which cannot be changed, from a predetermined set of standard components. Here, modularity is applied by means of a menu of options from which the service worker arranges or combines appropriate modules according to customer specification ( Sundbo, 1994 and Voss and Hsuan, 2009). Second, the customer can be presented with a prototype that can be tailored to suit an individual's needs and requirements ( Tiwana and Ramesh, 2002). Variety can be obtained by changing dimensions of the service prototype. Components in the standard design can be modified or unique modules can be created and added to the prototype to provide a service package that meets customer specification ( Voss and Hsuan, 2009).

In health care, first steps towards the application of modularity have been made (Bohmer, 2005, Chorpita et al., 2005, De Blok et al., 2010, Langlois and Savage, 2001 and Meyer et al., 2007). This fits the trend that can be seen in most Western health care systems where care clients and patients are given a more central position. Care providers are encouraged to be responsive to the needs of their clients and take client demand as the basis for care provision (e.g., Billings and Leichsenring, 2005). In this respect, the application of modularity in a care organization's products and processes might provide a way to accommodate individual demand while keeping costs under control, which is another pressing factor that healthcare providers must take into account (Breedveld et al., 2006 and de Gooijer, 2007). To integrate patient services of a large healthcare provider, Meyer et al. (2007), for example, propose a platform of processes common to all patient-care services, with modular sets of processes for individual services. The authors applied modularity to the planning of patient services across a care trajectory and showed that this can improve care and achieve financial efficiency. Bohmer (2005) advocates a more patient-oriented approach through seamless combination of standard treatment processes. Subsystems are selected from a pre-defined menu and combined to address those dimensions in which groups of customers have the same needs, thereby gaining advantages in cost, time, and quality. Still, each patient receives a different combination of standardized treatment components and, as such, is treated as unique. Chorpita et al. (2005) developed an architecture for design of modular therapeutic interventions and treatment plans to be adapted to individual needs. The authors identify potential advantages in terms of design efficiency, effectiveness, and efficacy. De Blok et al. (2010) shed light upon the design of modular care packages. The authors show how 
Blok, C. de, Meijboom, B., Luijkx, K., Schols, J. The human dimension of modular care provision: opportunities for personalization and customization. International Journal of Production Economics: 2013, 142(1), 16-26

generic packages can be adapted in order to achieve customization in the contents of the care package provided to an individual health care client.

From the examples it follows that the application of modularity in care, as in other service settings, has been looked upon mainly from a rather technical point of view, thereby largely reflecting its manufacturing origin. Emphasis is put on customization of the service offering through service architectures (Voss and Hsuan, 2009 and Chorpita et al., 2005), service platforms (Jiao et al., 2003, Meyer et al., 2007 and Pekkarinen and Ulkuniemi, 2008), and service sub-systems (De Blok et al., 2010, Bohmer, 2005, Meyer and DeTore, 1999 and Meyer and DeTore, 2001). However, health care delivery is characterized by intimate and extensive contact between health care professionals and health care clients. The relative importance of human and behavioral aspects in health services is likely to influence the application of technical manufacturing concepts. Thus, besides building on platforms and architectures, modular care provision should also be about making the face to face interactions responsive to client needs and values (McLaughlin and Kaluzny, 2000). The concept of personalization is concerned with achieving individualized interactions. Therefore, this concept can also be used to better match the needs of an individual customer.

\subsection{Personalization of service outcomes}

Personalization focuses on the way in which the services are delivered. It comes about by the adaptation of employee interpersonal behavior and in using individualized interactions and communications that fit a particular customer's preferences (e.g., Wind and Rangaswamy, 2001 and Zahay and Griffin, 2004). In addition, personalization concerns the manner in which service employees relate to

customers as people-cold and impersonal at the one end to warm and personal at the other (Mittal and Lassar, 1996). Personalization can be applied during the specification of the desired service package offered (Piller, 2007) as well as during service delivery (Gwinner et al., 2005 and Voss and Hsuan, 2009), as such covering the service process as a whole.

Two types of personalization in the service delivery process have been identified by Surprenant and Solomon (1987) in a banking context. First, pro-forma personalization gives the impression of personalized service by combining and adapting aspects as small talk, use of customers' names, etc. Even though, e.g., the name used is naturally different for each client, the mode of application of each proforma personalization aspect is fairly standardized, as such providing the service employee with a routinized and efficient script through which each customer gets the feeling of being approached as a unique individual. Second, attentive personalization tunes interactions and communication to the unique and specific needs of the customer. It is accomplished by deliberately combining and adapting interpersonal behavior aspects, such as vocabulary or personality style used, to fit service delivery to a particular client. As such, service employees employing attentive personalization recognize the customer as a unique individual and will hardly make use of repetitive and similar approaches among customers.

In health care contexts, the ability of professionals to adjust their interpersonal behavior in a situationally contingent manner increases client satisfaction and 
Blok, C. de, Meijboom, B., Luijkx, K., Schols, J. The human dimension of modular care provision: opportunities for personalization and customization. International Journal of Production Economics: 2013, 142(1), 16-26

compliance (Friedman and Churchill, 1987, in Gwinner et al., 2005). Furthermore, in care for elder people, Gilleard and Reed (1998) have shed light on the importance of personalization of care delivery to build feelings of empathy and concern. Moreover, teaching nurses how to attune themselves to an elder client's needs enables them to offer tailored care to each individual elder client (Caris-Verhallen et al., 1999). Even though these findings do not deliberately distinguish between pro-forma and attentive personalization, they clearly show the importance of adapting interpersonal behavior in order to tune supply to demand in care provision.

\subsection{A comparison of customization and personalization}

Based on the previous sections, Table 1 summarizes existing knowledge on customization (through modularity) and personalization. In this table it is demonstrated that both personalization and customization are used to tune something to individual customer preferences. However, both concepts work towards this outcome from a different focus. For customization, this is the contents of the service: the 'what' of service provision. For personalization, this is the way in which the service is delivered to the customer: the 'how' of service provision. From the different foci of the two concepts, it also follows that each might be offered with total lack of the other. For example, a front office employee could modify the content of a service package promptly and dutifully but in a mechanical fashion or a service employee could be warm and friendly when required yet ignore the need for adjustment of the service offering (Mittal and Lassar, 1996).

\section{[TABLE 1]}

Because of its focus on the content of service offerings, customization is especially important during the first phase of the service life cycle, during which the service is put together and fine-tuned. To achieve customization at this stage through one of the different applications of modularity, the service worker(s) interacting with the customer modifies the contents of the service package delivered. Personalization is of importance throughout the entire service life cycle. To achieve personalization over the service life cycle, the service worker(s) modify their interpersonal behavior and the way in which they approach the client during each and every contact point between service customer and service worker.

Even though the concepts of customization and personalization have been developed and presented as two separate concepts, recently the value of combining the two has also been identified. Because many services are produced and consumed simultaneously, attention can be given to the adaptation of service contents and the server worker's behavior at the same time (Gwinner et al., 2005 and Voss and Hsuan, 2009). The simultaneous practice of customization and personalization is highly desirable in environments where customers are not provided with a one-fits-all solution but with services they want and need, and where customers value being treated as individuals (Gwinner et al., 2005). This holds true particularly for the health care field (Berry and Bendapudi, 2007 and Dagger et al., 2007).

In summary, customization and personalization are complementary to each other in tuning modular care and service offerings to customer needs and preferences. To achieve overall tuning of care provision, we posit that a more structural integration of 
Blok, C. de, Meijboom, B., Luijkx, K., Schols, J. The human dimension of modular care provision: opportunities for personalization and customization. International Journal of Production Economics: 2013, 142(1), 16-26

customization and personalization aspects is required. Recalling the relative importance of human and behavioral aspects in health services, simultaneous application of either one of the two forms of customization and one or both forms of personalization is likely to result in a more complete, comprehensive and adequate tuning when providing care in a modular fashion.

\section{METHODOLOGY}

\subsection{Study context}

Case study methodology (Yin, 1993 and Voss, 2009) allows researchers to address “ how", "what" and "why" questions (Voss et al., 2002), such as the research question of the present study: How does personalization contribute to the provision of customized modular long-term care? Modularity in health care is a new emerging area. Moreover, the health care context necessitates addressing aspects of human behavior, i.e., to explore how human behavior affects modular production theory. Due to the innovative aspect of the subject, we have decided to follow a qualitative case study design. Case study research is particularly appropriate for areas where research and theory are at their early, formative stages ( Benbasat et al., 1987). It lends itself to exploratory investigations where the variables are still unknown and the phenomenon of study is not well understood ( Meredith, 1998), as is the case for personalization in relation to modularity (in service contexts). A particular strength of the case method is the opportunity to investigate the phenomenon in its real-life context ( Yin, 2003) that enables us to gain a deeper understanding of personalization and how it influences the adaptation of modular care provision. Finally, case study research facilitates triangulation of data through multiple methods of data collection and multiple sources of evidence, providing stronger support for results ( Eisenhardt, 1989 and Yin, 2003). We conducted our case study research in the Netherlands in the field of elder care. In particular, we focused on organizations that provide care and related services to elderly people living independently. Care for elder people is a huge issue in many countries, given the aging of populations, recurring reports of deficient service and fast-rising costs of care provision. In the Netherlands it is expected that the percentage of people aged 65 years or older will grow from $15 \%$ in 2010 to 26\% of the population in 2040 ( De Jong and Van Duin, 2010). This implies that there will be a significant number of older persons in need of long-term care in the decades to come ( Van Bilsen, 2008) causing an increase in long-term care expenditures from 3.5\% of GDP in 2010 to $8.1 \%$ in 2060 ( European commission, 2009) and requiring 30\% more professionals to meet increasing demand ( Van der Lucht and Polder, 2010).

To cope with these issues, the Dutch government reforms the long-term care system and promotes efficiency (Breedveld et al., 2006 and de Gooijer, 2007). In addition, health policies increasingly aim at facilitating greater and longer-lasting autonomy for older clients in their own homes, backed by a coherent supply of necessary support services (WHO and Van Campen and Woittiez, 2003). Moreover, calls are being made to give long-term care clients a larger say in the contents of care offerings, in order to stimulate customization and client-orientation (Gradus and Van Asselt, 2011). All these developments make care and service provision to elder people who live independently is an important area of inquiry. 
Blok, C. de, Meijboom, B., Luijkx, K., Schols, J. The human dimension of modular care provision: opportunities for personalization and customization. International Journal of Production Economics: 2013, 142(1), 16-26

Fig. 1 presents a brief and general overview of a health care sector as a whole and clarifies the focus of this study (i.e., boxes and arrows printed in bold). Organizations active in the field of care and service provision to elder people living independently, in general, face complex demands with which they have to deal. Since elder people live independently as long as possible, even when they need care and support (Schols, 2004), the issues surrounding care provision are extensive. Organizations typically offer their elder clients a package of heterogeneous care and related services, including components that concern home help, home nursing, welfare, and domestic services (e.g., Leichsenring et al., 2005 and Van Campen and Woittiez, 2003). Moreover, since elder people obviously differ amongst themselves in health status and preferences, each package will differ in its contents (Luijkx and De Blok, 2007). The provision of a care package will be mostly long-term, since full recovery from most functional impairments is often impossible (e.g., Van Bilsen, 2008). Therefore, care and service delivery is on-going and repetitive, since components are provided to the client every day or (a few times) each week. Over time, an elder client's needs and requirements are likely to alter as a result of changing health conditions that for elder people, generally speaking, will deteriorate (Van Bilsen, 2008). As such, the contents of a client's care package are subject to change.

\section{[TABLE 2]}

\subsection{Case selection and unit of analysis}

We decided to conduct multiple case research because analytic conclusions based on multiple cases are considered as more powerful (Yin, 2003). We chose to follow a purposive sampling strategy that allowed for literal replication, which means that we selected cases because they demonstrated the same phenomenon under study and are likely to provide similar results (Yin, 2003). Because little is known about the role of personalization in modular care provision, it was extremely valuable to observe the same phenomenon a number of times to gain general insights.

To bring about literal replication we controlled certain variables. For all case organizations, elder clients were the main client population. Besides, all cases provided a wide range of heterogeneous care and service parts, to be combined into a single package for each client. Finally, all organizations were certified with the Dutch care-related ISO9000 certificate (HKZ-certificate), meaning that their products and processes were registered and implemented in an established manner. In addition, we selected for maximum variation by deliberately varying the context of the organizations. To see whether a common pattern could be identified regarding the phenomenon under study (Miles and Huberman, 1994) cases were included with differing organizational backgrounds. Even though all cases selected provided care and services to elder people living independently at the time of our data collection, this was a recent development and their background was either in home care or residential care. Both types of organizations are highly prevalent in the Dutch sector for long-term elder care. Since we aimed to gain insight into personalization in relation to customized modular care provision to people living independently, data collection in both types of organizations was essential for our research. Whereas home care organizations traditionally have a rather mono-dimensional service range focusing mainly on care, residential care providers supply a multi-dimensional range 
Blok, C. de, Meijboom, B., Luijkx, K., Schols, J. The human dimension of modular care provision: opportunities for personalization and customization. International Journal of Production Economics: 2013, 142(1), 16-26

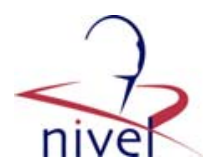

of service parts, encompassing care, welfare, and housing. Moreover, home care professionals provide care components in a client's home and then leave again to go to the next client. Conversely, professionals in residential care work in close proximity to their clients, since these clients live together in a single premises. The differences in history are likely to provide us with ample insight in the possibilities for customization as well as the nature and depth of personalization.

Table 2 summarizes some basic information and the characteristics relevant to our case selection of the four organizations included in this case research. Because of a merger, cases $\mathrm{K}$ and $\mathrm{T}$ became part of one single organization, with very independently working units. Basic information on the number of clients, number of service workers and turnover, however, could only be provided at the level of the overall organization.

We conducted our study from the point of view of care professionals. Front-line service employees are in an optimal position to link the service organization and its customers. They are responsible for understanding customer needs and responding to customer requirements in real-time (Cook et al., 2002) and thus have the ability to practice both customization and personalization (Bitran and Pedrosa, 1998). We took the total care process as our unit of analysis since the various forms of both customization and personalization can be expected to appear in different process stages. It has been suggested that the total care process can be divided into three phases, being a-priori specification, on-the-job adaptation and on-going delivery of care packages (De Blok et al., 2010). During a-priori specification a generic

assessment of a client's needs and requirements takes place, based on which a care

package is constructed from the care provider's available range of components. After this phase, care delivery starts. During on-the-job adaptation, client and professional together experience the delivery of care and service components. This results in an in-depth assessment of the client's needs and subsequent adaptation and fine-tuning of components and delivery aspects. After some time, all needs and preferences will be known, the client's care package is settled, and component delivery will be ongoing from this point onwards. Over time, adjustments in the care package will probably be necessary because of changing client circumstances. Steps taken during package adaptation, however, are largely similar to the subsequent steps of a-priori specification and on-the-job adaptation, followed again by on-going care delivery.

We see, therefore, the care process sketched out as a cyclical one in which the client' $\mathrm{s}$ care package is configured and re-configured up and until the point where the elder client leaves the care process because of recovery or death.

\subsection{Data collection and analysis}

One should have a prior view of the general constructs or categories to be studied and their relationships (Voss et al., 2002). To this end, the characteristics of customization and personalization as compared and contrasted in Table 1 serve to guide our empirical work in the context of long term care provision to elder people living independently. Data collection, data analysis and reporting, thus, focused on customization of the modular care package, personalization of care provision and the 
Blok, C. de, Meijboom, B., Luijkx, K., Schols, J. The human dimension of modular care provision: opportunities for personalization and customization. International Journal of Production Economics: 2013, 142(1), 16-26

possible connections and interactions between the two concepts when working towards the tuning of modular care services.

To acquire a thorough overview and understanding of personalization and customization in the configuration of modular care packages, data gathering was guided by a data collection protocol. This aided the reliability and validity of data (Yin, 1993). The protocol comprised a topic list on the subjects to be covered with respect to modularity, customization, and personalization to be addressed in relation to the total care process (Eisenhardt, 1989). Multiple sources of evidence were used for data collection to facilitate a process of triangulation (Eisenhardt, 1989). The main method of data collection was semi-structured interviews. In all cases, multiple respondents were interviewed to enhance the reliability of our data (Voss, 2009). The respondents in each case were, by job title: regional director, team leader home nursing, team leader home help, front desk employees, start-up nurses, key nurses and representatives from complementary services, call centers, and marketing. In total, 38 interviews were conducted generally lasting from 1 to $2 \mathrm{~h}$. The interviews were recorded and transcribed verbatim to contribute towards the reduction of observer bias (Voss, 2009). After transcription the interview texts were sent back to the interviewees to check the interview contents, which helped to obtain a higher degree of validity. To further improve the validity of the data, the interviews were complemented by examination of relevant documentation (e.g., handbooks, process descriptions, and product books), and each case involved three one-day field visits to observe and experience the working processes. Narratives of each case were documented by combining the transcripts, documents and notes, ideas and insights that arose during the field visits. To increase the accuracy of the narratives, key informants of each case were consulted regularly over the course of data collection and analysis (Voss, 2009).

In order to reduce the data we collected in the case studies we coded the transcribed interviews, as well as the notes made during the observation visits. In order to improve the validity and reliability of the study, we used the qualitative data analysis software Atlas.ti 5 (Atlas.ti, 2004) to manage the coded data. Using software contributed to more systematic analysis procedures and guard against informationprocessing biases (Miles and Huberman, 1994 and Eisenhardt, 1989).

We have followed the three-step coding scheme of Strauss and Corbin (1998). First, the interviews were coded using a generic, initial codes list since it is often advisable to limit the number of categories (Voss et al., 2002). Each interview was coded independently by two researchers who then compared and discussed their codes to reach consensus on each of them. During this process, the codes list was expanded to encompass emerging themes and cover the richness and nuances of the data collected. Second, we bundled text fragments with similar codes and systematically analyzed their contents to reveal the core concepts related to personalization and customization. We were thus able to get insight into the different (sub) categories involved. Finally, we related both concepts to the consecutive steps taken during the care process. In this way we developed insights into the mutual relations among the categories both within and across the cases. The findings resulting from this threestep coding process are presented in the next section.

\section{EMPIRICAL RESULTS}


Blok, C. de, Meijboom, B., Luijkx, K., Schols, J. The human dimension of modular care provision: opportunities for personalization and customization. International Journal of Production Economics: 2013, 142(1), 16-26

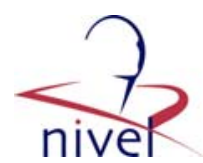

Our empirical analyses indicated that both customization and personalization were present in the provision of care packages. Customization involved the configuration of the care package itself, as a nurse pointed out: "We have to assess for each client what he can do himself and what we have to do for this client. That is totally dependent on each person 's situation. So which combination of parts we ultimately deliver to each client is all tailor made". It was primarily achieved during a-priori specification and on-the-job adaptation. At the same time, care professionals in the case organizations largely emphasized the need for tuning of personal interactions and communications to a client's preferences. The perceived high degree of importance of this, in addition to customization was stressed by one manager as follows: "Care is just care, in whatever combination it is offered, however, true distinctions can be made in the experience provided to clients and in the way in which clients are treated and addressed". Personalization, i.e., employees modifying their interpersonal behavior among clients, was realized in all phases of the care process. In the following sections, we will present our findings with respect to customization and personalization in terms of our theoretical framework. Since we aim to gain insight into the contribution of personalization in the context of modular care provision, our main emphasis will be on this concept.

\subsection{Customization}

In each case, the data indicated that customization of care offerings was achieved during the first two phases of the care process. In the a-priori specification phase, a preliminary care package was set up for each client, starting from either a menu of options or a package prototype. In cases $\mathrm{K}$ and $\mathrm{T}$, a combination of standard components was compiled from a menu. Variation was achieved by mixing and matching components from the total range of supply: "Because of the combination of the standardized components, we come to a more or less fit-to-size package for each client" (manager case T). A typical package might contain assistance with heavy household work, assistance with showering and getting dressed, meals-on-wheels, and financial advice. In cases $\mathrm{R}$ and $\mathrm{V}$, a prototype was taken as a starting point, dimensions of which were changed later on in the care process. In case $\mathrm{V}$, for example, prototypes existed for various diseases and old age constraints: "All current and potential future issues that can occur for a particular constraint or disease, such as diabetes or cancer, are described in a way that clarifies what components are required" (manager case V). Relevant care and service components were linked to the various stages of a constraint or disease. These components formed the basis of the care package that a client would receive in a certain stage.

Then, in all four of the cases, and thus independent from the starting point for package development (i.e., menu of options or prototype), various dimensions of the preliminary package were changed and adapted during the on-the-job adaptation phase. On the one hand, content-related functionalities of components were altered. For example, the generic component of domestic care comprised the execution of all 
Blok, C. de, Meijboom, B., Luijkx, K., Schols, J. The human dimension of modular care provision: opportunities for personalization and customization. International Journal of Production Economics: 2013, 142(1), 16-26

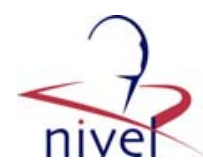

household chores by the home help nurse for one client because of this client's severe problems with bending and stretching. Another client preferred or was able to help with small and light tasks such as dusting. On the other hand, adaptations concerned the execution of a component. Nurses in all cases indicated that a component's time of delivery, frequency, duration, and intensity could be varied for different clients. Thus, by first developing a preliminary package and then changing dimensions of component contents and execution-related aspects, the care package as a whole was customized for each client in two phases. As such, it was ensured that each client received all care and related service parts that answered his ailments or old age constraints and that these parts were delivered in the client's preferred manner.

\subsection{Personalization}

The data revealed the effectuation of both pro-forma personalization and attentive personalization in all stages of the care process. Besides, the data indicated two distinctive forms of attentive personalization, being the adaptation of communication and interaction and the matching of personality types.

\subsubsection{Pro-forma personalization}

In all stages of the care process, examples were found of professionals making personal references to clients with the goal of letting elder people experience warmth, trust, and confidence. In all cases, the use of pro-forma personalization started during a-priori specification, where nurses and front desk workers wanted clients to feel welcome in their organization: "My primary goal is to break the ice and make the client feel comfortable. Thereafter, I arrange everything that has to be arranged so care delivery for a client can start" (front desk employee case T). During on-the-job and on-going care delivery, pro-forma personalization was practiced when a professional entered a client's home. In each case, clients were often greeted by using their names. Subsequent small talk often made reference to topics that had been discussed with the client during previous times of care provision, such as the grandchildren, an outing, or a recent cold. Thereafter, the accomplishment of pro-forma personalization continued during the execution of components: "While you are putting on support stockings, you make sure these stockings are put on in the right way, but at the same time, you ask how the elder client is doing" (nurse case $\mathrm{K}$ ).

\subsubsection{Attentive personalization}

Attentive personalization appeared in two forms: matching of interaction patterns and communication and matching of people. Matching and adaptation of interaction and communication were identified during specification and delivery of care packages. When starting the needs assessment during the a-priori specification phase, professionals adopted a very respectful attitude because they stepped into a very 
Blok, C. de, Meijboom, B., Luijkx, K., Schols, J. The human dimension of modular care provision: opportunities for personalization and customization. International Journal of Production Economics: 2013, 142(1), 16-26

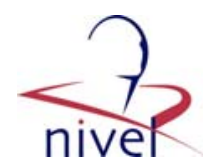

personal situation. "Well, you step into someone's house, don 't you, and you're a guest there" (nurse case V). Besides, the amount of information provided during this phase was adapted to a client's needs and requirements. For example, professionals indicated that some clients who were about to go home from a hospital stay did not want to receive too much information about the home care they were about to receive. They just wanted to go home, so information provided to these clients was as summary as possible. Interaction and communication styles used were also adapted to preferences and abilities of clients: "We have all sorts of clients, from people in high-income districts to people in working-class neighborhoods. They are often different from each other so you treat and approach them differently and explain things in a different way" (nurse case R).

Considered matching of people took place by matching the personalities of clients with those of professionals. This appeared primarily during early stages of the care process. During a-priori specification, personality matching took place simultaneously with the needs assessment for particular care services: "After I have spoken extensively to the client, I know my bird, and I have assessed what services a client requires and with which of my home help workers this person will match" (team leader home help case K). If a client did not get on well with a professional, the client was assigned another professional later on in the care process.

Personality matching was particularly emphasized for service types that were provided for a couple of hours in a row, thus having a high interpersonal contact intensity. Examples were home help and palliative care. Here, the professional was present in the house of a client for 3 or $4 \mathrm{~h}$ at a time, which made a personal match very important. "We have some very energetic professionals and some clients might feel threatened by that. While other clients say: perfect, I don 't have to say or do anything and my whole house is clean in a couple of hours. So it's very much a matter of the right match" (regional director case V). The case data hardly revealed people matching for care services that had a shorter duration, such as personal care (e.g., washing, getting dressed, assistance with visiting the toilet), provision of medicines or assistance with eating and drinking. For these services, first priority was to provide all clients with the care components to which they were entitled each day, irrespective of who was providing these services. Interviewees indicated that time pressure and an insufficiently large pool of personnel seemed to cause a lack of flexibility because of which organizations could not match personalities for these types of services, even though these represented some of the most intimate components of care provided.

In summary, the case data indicated that both customization and personalization were used to adapt care provision to individual client's requirements and preferences. Especially during the first two stages of the care process, a-priori specification and on-the-job adaptation, customization and personalization are practiced simultaneously. During on-going care delivery the customized care package was 
Blok, C. de, Meijboom, B., Luijkx, K., Schols, J. The human dimension of modular care provision: opportunities for personalization and customization. International Journal of Production Economics: 2013, 142(1), 16-26

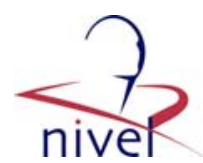

brought into practice and personalization was used to adapt interpersonal behavior during care delivery.

None of the cases limits itself to the use of merely one form of customization through the use of modularity. Rather, all cases use a combination. They start with either a menu of options or a prototype to form a generic package of care and service parts for each client. Then, independent of the starting point used, dimensions of components in the generic package are assessed in more detail.

In addition to the existence of pro-forma personalization throughout the care process, the case data revealed two forms of attentive personalization, adaptation of interaction and communication and personality matching. These were also observed throughout the care process. A summary of the means used for tuning supply to demand throughout the various phases of the care process is given in Fig. 2.

\section{[FIGURE 2]}

\subsection{Personalization as a means to achieve customization}

During the interviews, it was often emphasized that once a customized care package had been configured for a particular client, this packages was by no means fixed over time. During the course of care provision, changes might be required. For some clients, this would be already after some weeks, for others changes could occur only after months or even years of care provision. Customization of care contents, thus, would come back once in a while for each client, due to changes in this client's health situation. This has been shown in the upper row of Fig. 2.

Personalization, thus, occurs over the course of the care process (see Fig. 2) and (re)customization of a care package is required once something changes in a client's situation. This gave rise to the notion that there was likely to be another type of relation between the concepts of customization and personalization in addition to the complementarities that we had identified so far. To enable further in-depth data analysis text segments that had been simultaneously coded with codes related to customization and personalization were extracted. We systematically analyzed these segments by not only relating the codes to the consecutive steps of the care process, but also to each other, thereby extending our data analysis as explained in Section 3.3. In this way, we developed insight into the mutual relations among the concepts of customization and personalization over the course of the care process. The in-depth analysis revealed that the interviewees identified personalization as a means to effectuate customization: "By approaching the client in the way he desires, professionals are often able to build a good relationship with their clients. This might lead to many good things both for the client and our organization "(team leader home care case K). Interviewees indicated that because each client was treated and addressed in his or her preferred manner, they felt comfortable enough to talk about their health and the constraints from which they were suffering. Moreover, interviewees related personalization to the ability to customize care packages over time. One team leader phrased this as follows: "A good connection between a client and her home help professional might be important for the realization of other care services. Because of their relationship we can make sure we offer the client those 
Blok, C. de, Meijboom, B., Luijkx, K., Schols, J. The human dimension of modular care provision: opportunities for personalization and customization. International Journal of Production Economics: 2013, 142(1), 16-26

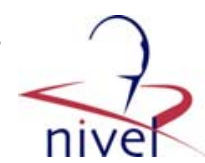

services parts he or she is in need of over time" (team leader home care case R).

Even when a client increasingly perceived worsening or new problems, he or she would be likely to tell the professional about this because of their relationship. Personalization of care provision, thus, appeared ultimately to give professionals the opportunity to assess a client's needs more deeply. Personalization, thereby, had an important function in bringing to light opportunities and necessities for customization of the modular care package over time. With the information received from the client, professionals, were able to take action on the changes in the client's health status and put things in motion for the adaptation or extension of the modular care package along with changes in a client's requirements.

This insight indicates that the 'what' and 'how' of service provision are very much intertwined, meaning that the way in which the service is provided results in a certain connection between service professional and elderly client, which in turn influences the ability to adapt the contents of the service delivered when required. Given that the cycle of 'change detection-embeddings change in the service offering' will likely come back at least several times during the period that an elderly client receives care from a care provider, the empirical results indicate that personalization achieves customization over time.

\section{DISCUSSION}

Our case results indicated that both customization and personalization were vital in tuning modular care packages to client needs and preferences. Customization of care packages was achieved by combining components from a menu or selection of a package prototype and subsequent adaptation of the package contents. In order to customize care and services according to individual needs, care professionals in the case organizations aimed to understand the individual clients holistically. To achieve this, personalization aspects played a vital role. Simultaneous practice of customization and personalization was thus observed in the provision of modular care provision to elderly clients, making our case research suited to provide empirical insight into how personalization is practiced in concurrence with customization and the effects of simultaneous practice.

In general, literature has argued that in service environments characterized by intimate, prolonged, and emotionally charged contact, such as the provision of long term elderly care, it is important to leave room for 'service-minded' behavior of professionals (Lanjananda and Patterson, 2009). More specifically, there should be openness to situational contingency and thus the ability to fine-tune the way in which a service is provided to a wide variety of contextual circumstances based on professional judgment and discretion (Langlois and Savage, 2001). Remarkably, however, the case data revealed that professionals partially standardized their interpersonal interaction with elder clients. For example, the way in which elder clients were greeted was standardized as was the use of small talk. These types of interactions could thereby be performed by professionals without requiring much thought and effort. Still, they provide clients with a comfortable feeling; elder people 
Blok, C. de, Meijboom, B., Luijkx, K., Schols, J. The human dimension of modular care provision: opportunities for personalization and customization. International Journal of Production Economics: 2013, 142(1), 16-26

value being served and approached in a consistent manner over time since this makes interactions predictable (Essén, 2008). Also the adaptation of information to and communication with elder clients showed many characteristics of standardization. Different types of clients were approached in different manners, however, within a client segment (such as elder clients who were just released from a hospital), the way in which interactions were given shape showed many similarities. This is appreciated by elder clients since a certain degree of standardization of interpersonal interaction aspects among clients contributes to a uniform appearance of the care organization as a whole (Essén, 2008). Thus, health care practice in our case studies shows that rather standardized forms of personalization can be as service-minded as openness to all kinds of contextual circumstances, as emphasized in current literature. A sole focus on complete openness in interpersonal behavior might lead to missed opportunities in terms of combining efficient and high-quality care provision. From our empirical research it follows that the practice of personalization both complements and effectuates customization in the provision of elderly care. Complementarity of personalization and customization had been identified in literature on modular service provision (Gwinner et al., 2005 and Voss and Hsuan, 2009) and following our case results also holds in a very specific sub-section of the service sector, being care and service provision to elder clients. By means of personalization, variation was achieved in how clients were approached and treated in addition to variation in the contents of the care offering that was achieved by customization.

The insight that personalization has the ability to effectuate customization, however, has not been identified in previous research on personalization. Up to now, the concept of personalization has been associated with building loyalty and client satisfaction (Friedman and Churschill, 1987, in Gwinner et al., 2005 and Zahay and Griffin, 2004). Our case studies show that personalization also acts as a means to build rapport, i.e., a sense of genuine sensitivity and concern perceived the by client (Ashforth and Humphrey, 1993. Because of the perceived relationship, elder clients are more comfortable and willing to share information about their personal situation.

This enables professionals to assess the fit between a client's needs and his or her customized care package, and adapt this package when required. Personalization, thus, is required to achieve the ability to customize a service to a customer's specification. For the provision of care and services, this implies that co-creation of value not only requires that service professionals and clients are able to design and combine the desired contents of the service offering but also that they are able to build a relationship based on trust and openness.

Moreover, our findings indicate that the increased ability to customize a care and service offering occurs not only in a single care process but also over time. Care provision to independently living elderly may continue over years, especially when these elderly are backed by an appropriate supply of care and services. Over time, however, an elder client's needs and requirements are likely to alter as a result of changing health conditions that, generally speaking, will deteriorate (Van Bilsen, 2008). As such, the contents of a client's care package are subject to change and failing to properly reconfigure various types of components might have severe consequences for a client's quality of life. Personalization enables care providers to 
Blok, C. de, Meijboom, B., Luijkx, K., Schols, J. The human dimension of modular care provision: opportunities for personalization and customization. International Journal of Production Economics: 2013, 142(1), 16-26

supply the right configuration of care services over the entire period of care provision. Personalization in that sense provides the link that makes the process of care package configuration and care package delivery cyclical, by giving insight into the changes that have to be configured back into the care package.

The need for service configuration following changes in customer needs and requirements over time stretches beyond the elderly care sector. In other service contexts, such as financial services including banking and insurance, the need for adapting service offerings throughout various stages in customer's lives has been suggested (Zeithaml et al., 2006). By providing services that continuously seek to satisfy the lifestyle and need patterns of individual customers, the life-span of the customer with the organization can be lengthened. To achieve this, service organizations have to integrate personalization aspects to be performed by service professionals with a modular service setup to be used to mix-and-match service components in a customized service package.

In sum, despite the development of customization and personalization as two separate streams of research (see Table 1), this study shows that clear linkages do exist. Because of its focus on the way in which the service is delivered by means of adapting interpersonal interactions between service professionals and clients, clients feel comfortable enough to share information about their personal (health) situation. This, in turn, enables the focus and outcome of customization, i.e., adaptation of the content of the service to customer needs and requirements. Since personalization is practiced throughout the life cycle of a service package, so both during package configuration and package delivery, changes can be detected in a client's situation and a new or adapted service package can be configured, thus enabling customization of the care contents over time. As such, the cyclical nature of modular care provision is stimulated.

\section{CONCLUSIONS}

The trend towards the provision of client centered care forces providers of long-term care to be more responsive to the needs and desires of their elder clients. To cope with heterogeneous and multiple demands, the application of modularity is increasingly proposed in care and services. However, even though needs of care clients have been identified with respect to well-tuned interpersonal interactions (Berry and Bendapudi, 2007, Dagger et al., 2007 and McLaughlin and Kaluzny, 2000), prior research on modularity has focused merely on customization of care contents. This study begins to bridge this gap by simultaneous consideration of customization and personalization in the provision of modular care packages. The simultaneous deployment and contribution of these concepts has not been explored before in a health care context. More specifically, this paper aims to develop our understanding of how personalization contributes to the adaptation of modular care provision, thus taking into account behavioral aspects in the application of a rather technical operating system.

Our research provides insight in the complementarity of customization and personalization. Although both concepts are used to better match the needs of an individual customer, they work towards this outcome from a different focus. For 
Blok, C. de, Meijboom, B., Luijkx, K., Schols, J. The human dimension of modular care provision: opportunities for personalization and customization. International Journal of Production Economics: 2013, 142(1), 16-26

customization, this is the contents of the service: the 'what' of service provision. For personalization, this is the way in which the service is delivered to the customer: the " how' of service provision. Moreover, our empirics show that personalization effectuates customization. Personalization appeared to be an important means to bond with clients. The relationships built serve as a means to achieve customization of care packages over time. Whereas in service management and marketing literature the practice of personalization has often been related to outcomes such as satisfaction and loyalty, its effect in elder care can be extended beyond these outcomes.

\subsection{Managerial implications}

From a managerial perspective, the provision of care packages that are well tuned to the needs and preferences of individual clients is likely to become one important aspect of success in the current health care environment.

Our findings seem relevant for managers responsible for designing and implementing care delivery systems. This research shows that customization possibilities occur at the start of the care process whereas possibilities to practice personalization appear throughout this same process. By carefully designing opportunities for customization and personalization, care organizations can begin to work towards comprehensive tuning of their care packages offered in order to effectuate client-centered care provision. More specifically, we suggest to apply modularity as an overarching structure to integrate customization and personalization. To achieve this, care providers should not only take into account possibilities for separation and recombination of care content components, but also make sure personal interaction aspects can be separated and recombined. Modularity in content components would enable the core package of care and services to be customized to elder client's needs and requirements. Subsequently, modules representing forms of personalization will cover supplementary service related activities and add value and differentiation to the customer's overall experience. Together, the customized core and personalized supplementary service parts form the augmented service or service concept that is offered to each client ( Lovelock and Wirtz, 2007).

Beside such a stepping stone towards care package design that allows for comprehensive tuning, our findings provide guidance for managers responsible for care delivery in that they should recognize the importance of personalization in both complementing and effectuating customization. Consistent application of various types of personalization is likely to influence positively the relationships that care professionals build with their clients. Besides, the often difficult to assess needs, requirements, and preferences of elder clients, that professionals largely learn about by experience ( Essén, 2008), could be eased by a conscious and structured use of personalization. Managers, therefore, should support their care professionals in the employment of personalization throughout the care process, thus leveraging/exploiting the cyclical nature of customization due to consequences arising from personalization.

Our research could inform human resource management practices. In an environment where customers increasingly value tuning of care provision to both their medical and human interaction needs, the recruitment of professionals who 
Blok, C. de, Meijboom, B., Luijkx, K., Schols, J. The human dimension of modular care provision: opportunities for personalization and customization. International Journal of Production Economics: 2013, 142(1), 16-26

have the ability and willingness to practice both customization and personalization in a modular setup might influence greatly customer evaluations. Furthermore, training service employees in how they can better or more consistently apply various forms of customization and personalization might positively influence relationships built with elder clients.

\subsection{Limitations and future research}

The case method used in this study has both strengths and weaknesses. We used the cases to provide a richer understanding of a new phenomenon and to explore related extensions to existing theory (Voss et al., 2008). Our findings hold for all cases investigated, even though these cases differed from each other in various aspects. Still, the relatively small number of cases might limit the generalizability of our findings.

We carefully narrowed down the context of our research to the care-for-the-elderpeople sector. Because of the close and intimate interactions between professionals and their elder clients, it proved to be a very suitable research environment for the simultaneous exploration of customization and personalization. However, the definition of our research context raises the question to what extent our findings apply to other healthcare and service contexts.

To address these limitations, further research is needed, research that examines our findings in the context of a wider set of care organizations, by means of both qualitative and quantitative research. Moreover, to avoid industry-specific findings and create a full picture of the essence and role of personalization, future research should focus on a range of service sectors in which modular service packages are provided. To extend the research context, the often used typology that distinguishes among people processing services (e.g., elder care), information processing services (e.g., banking), and possession processing services (e.g., car maintenance) (e.g., Chase and Tansik, 1983 and Wemmerlov, 1990) could serve as guidance. The importance and possible integration of personalization could be explored within as well as among the service categories in this typology.

Additionally, to get the full picture of care and service adaptation, future research should be conducted from a client's point of view. Combining insights on personalization provided by clients and service workers will give a balanced view of the practice of value co-creation involving both customization of the service offering and personalization of the interpersonal interaction.

\section{REFERENCES}

Ashforth and Humphrey, 1993 B.E. Emotional labor in service roles: The influence of identity,

" Academy of Management Review, 18 (1) (1993), pp. 88-115

Atlas.ti, 2004, User's Manual for ATLAS.ti 5.0, 2nd edn., Scientific Software Development, Berlin.

Baldwin and Clark, 1997, Managing in an age of modularity Harvard Business Journal, 75 (5) (1997), pp. 84-93

I. Benbasat, D.K. Goldstein, M. Mead The case research strategy in studies of information systems MIS Quarterly, 11 (3) (1987), pp. 369-386 
Blok, C. de, Meijboom, B., Luijkx, K., Schols, J. The human dimension of modular care provision: opportunities for personalization and customization. International Journal of Production Economics: 2013, 142(1), 16-26

E. Bendoly, K. Donohue, K.L. Schultz Behavior in operations management: assessing recent findings and revisiting old assumptions Journal of Operations Management, 24 (6) (2006), pp. $737-752$

L.L. Berry, N. Bendapudi Health care: A fertile field for service research Journal of Service Research, 10 (2) (2007), pp. 111-122

J. Billings, K. Leichsenring Integrating Health and Social Care Services for Older Persons Ashgate Publishing, Aldershot (2005)

G. Bitran, L. Pedrosa A structured product development perspective for service operations European Management Journal, 16 (2) (1998), pp. 169-189

R.M.J. Bohmer Medicine's service challenge: Blending custom and standard care Health Care Management Review, 30 (4) (2005), pp. 322-330

R. Bosman, G.J.J.W. Bours, J. Engels, L.P. De Witte Client-centred care perceived by clients of two Dutch homecare agencies: A questionnaire survey International Journal of Nursing Studies, 45 (4) (2008), pp. 518-525

E.J. Breedveld, B.R. Meijboom, A.A. de Roo Labour supply in the home care industry: A case study in a Dutch region Health Policy, 76 (2) (2006), pp. 144-155

W.M.C.M. Caris-Verhallen, I.M. De Gruijter, A. Kerkstra, J.M. Bensing Factors related to nurse communication with elderly people Journal of Advanced Nursing, 30 (5) (1999), pp. 1106-1117

R.B. Chase, D.A. Tansik The customer contact model for organization design Management Science, 29 (9) (1983), pp. 1037-1050

B.F. Chorpita, E.L. Daleiden, J.R. Weisz Modularity in the design and application of therapeutic interventions Applied and Preventive Psychology, 11 (3) (2005), pp. 141-156

L.S. Cook, D.E. Bowen, R.B. Chase, S. Dasu, D.M. Steward, D.A. Tansik Human issues in service design Journal of Operations Management, 20 (2) (2002), pp. 159-174

T.S. Dagger, J.C. Sweeney, L.W. Johnson hierarchical model of health service quality: Scale development and investigation of an integrated model Journal of Service Research, 10 (2) (2007), pp. 123-142

C. De Blok, K. Luijkx, B. Meijboom, J. Schols Modular care and service packages for independently living elderly International Journal of Operations and Production Management, 30 (1) (2010), pp. 75-97

De Jong, A. \& Van Duin, C. (2010). Regionale prognose 2009-2040: Vergrijzing en omslag van groei naar krimp (Regional Forcast: Aging and Change from Population Growth to Shrinkage). Bilthoven, Planbureau voor leefomgeving.

R. Duray, P.T. Ward, G.W. Milligan, W.L. Berry Approaches to mass customization: Configurations and empirical validation Journal of Operations Management, 18 (6) (2000), pp. 605-625

B. Edvardsson, A. Gustafsson, I. Roos Service portraits in service research: A critical research International Journal of Service Industry Management, 16 (1) (2005), pp. 107-121

K.M. Eisenhardt Building theories from case study research Academy of Management Review, 14 (4) (1989), pp. 532-550

A. Essén Balancing standardization and customization in the public elderly care setting International Journal of Mass Customisation, 2 (3/4) (2008), pp. 324-340

European commission - European Communities (2009). 2009 Aging Report. Luxembourg: Office for Official Publications of the European Communities. C. Gilleard, R. Reed Validating a measure of patient satisfaction with community nursing services Journal of Advanced Nursing, 28 (1) (1998), pp. 94-100 
Blok, C. de, Meijboom, B., Luijkx, K., Schols, J. The human dimension of modular care provision: opportunities for personalization and customization. International Journal of Production Economics: 2013, 142(1), 16-26

W. de Gooijer Trends in EU Health Care Systems Springer Science, New York (2007) R. Gradus, E.J. Van Asselt De langdurige zorg vergeleken in Nederland en Duitsland ESB, 96 (4607) (2011), pp. 202-204

K.P. Gwinner, M.J. Bitner, S.W. Brown, A. Kuman Service customization through employee adaptiveness Journal of Service Research, 8 (2) (2005), pp. 131-148

J. Hsuan, T. Skjøtt-Larsen Supply-chain integration: implications for mass customization, modularization and postponement strategies Production Planning and Control, 15 (4) (2004), pp. 352-361

E. Jaakkola, A. Halinen Problem solving within professional services: Evidence from the medical field International Journal of Service Industry Management, 17 (5) (2006), pp. 409429

R.J. Jiao, Q. Ma, M.M. Tseng Towards high value-added products and services: mass customization and beyond Technovation, 23 (2003), pp. 809-821

R.N. Langlois, D.A. Savage Standards, modularity and innovation: The case of medical practice

R. Garud, P. Karnoe (Eds.), Path Dependence and Creation, Lawrence Erlbaum Associates, Mahwah, N.J (2001) P. Lanjananda, P.G. Patterson Determinants of customer-oriented behavior in a health care context Journal of Service Management, 20 (1) (2009), pp. 5-32

E.J. Lanseng, T.W. Andreassen Electronic healthcare: A study of people's readiness and attitude toward performing self-diagnosis International Journal of Service Industry Management, 18 (4) (2007), pp. 394-417

K. Leichsenring, G. Roth, M. Wolf, A. Sissouras Moments of truth. An overview of pathways to integration and better quality in long-term care J. Billings, K. Leichsenring (Eds.), Integrating Health and Social Care Services for older persons, Ashgate Publishing, Aldershot (2005)

Lovelock, C. H., Wirtz, J., 2007. Services Marketing. Pearson Prentice Hall, Upper Saddle River, NJ. K. Luijkx, C. De Blok Diversity among the elderly, diversity in approach

H. Moerbeek, A. Niehof, J., van Ophem (Eds.), Changing Families and Their Lifestyles, Wageningen Academic Publishers, Wageningen (2007)

C.P. McLaughlin, A.D. Kaluzny Building client centered systems of care: Choosing a process direction for the next century Health Care Management Review, 25 (1) (2000), pp. 73-82

M.H. Meyer, A. DeTore Product development for services Academy of Management Executive, 13 (3) (1999), pp. 64-76

M.H. Meyer, A. DeTore Perspective: Creating a platform-based approach for developing new services Journal of Product Innovation Management, 18 (3) (2001), pp. 188-204

M.H. Meyer, E. Jekowsky, F.G. Crane Applying platform design to improve the integration of services across the continuum of care Managing Service Quality, 17 (1) (2007), pp. 23-40

J. Meredith Building operations management theory through case and field research Journal of Operations Management, 16 (4) (1998), pp. 441-454

M.B. Miles, A.M. Huberman qualitative Data Analysis (second edn.)Sage Publications, Inc, Thousand Oaks (1994)

M. Miozzo, D. Grimshaw Modularity and innovation in knowledge-intensive business services: IT outsourcing in Germany and the UK Research Policy, 34 (9) (2005), pp. 14191439

B. Mittal, W.M. Lassar The role of personalization in service encounters Journal of Retailing, 72 (1) (1996), pp. 95-109

M.A. Moliner Loyalty, perceived value and relationship quality in healthcare services Journal of Service Management, 20 (1) (2009), pp. 76-97

M. Muffato Platform strategies in international new product development International Journal of Operations and Production Management, 1 (5/6) (1999), pp. 449-459 
Blok, C. de, Meijboom, B., Luijkx, K., Schols, J. The human dimension of modular care provision: opportunities for personalization and customization. International Journal of Production Economics: 2013, 142(1), 16-26

S. Pekkarinen, P. Ulkuniemi Modularity in developing business services by platform approach International Journal of Logistics Management, 19 (1) (2008), pp. 84-103

F. Piller Observations on the present and future of mass customization International Journal of Flexible Manufacturing Systems, 19 (4) (2007), pp. 630-636

B.J. Pine Mass customizing products and services Planning Review, 21 (4) (1993), pp. 6-13

F. Salvador Toward a product system modularity construct: Literature review and reconceptualization IEEE Transactions on Engineering Management, 54 (2) (2007), pp. $219-240$

S.E. Sampson, C.M. Froehle Foundations and implications for a proposed unified services theory Production and Operations Management, 15 (2) (2006), pp. 329-343

M.A. Schilling Toward a general modular systems theory and its application to interfirm product modularity Academy of Management Review, 25 (2) (2000), pp. 312-334

J.M.G.A. Schols De toekomst van de chronische zorg, ons een zorg? (Eng.: The Future of chronic Care, Who Cares?) (inaugural lecture)Dutch University Press, Amsterdam (2004)

$\mathrm{S}$. Sofaer, K. Firminger Patient perceptions of the quality of health services Annual Review of Public Health, 26 (2005), pp. 513-559

Starr, M.K. (1965), Modular production—a new concept. Harvard Business Review, Vol. 53

No. November-December, pp. 131-142.

A. Strauss, J. Corbin Basics of qualitative research (2nd edn.)Sage Publications, Thousand Oaks, Ca (1998)

J. Sundbo Modularization of service production and a thesis of convergence between service and manufacturing organizations Scandinavian Journal of Management, 10 (3) (1994), pp. 245-266

J. Sundbo Management of innovation in services The Service Industries Journal, 17 (3) (1997), pp. 432-455

C.F. Surprenant, M.R. Solomon Predictability and personalization in the service encounter Journal of Marketing, 51 (1987), pp. 86-96 No. April

A. Tiwana, B. Ramesh

Knowledge management in e-services: From mass customization to service individualization P.B. Lowry, J.O. Cherrington, R.R. Watson (Eds.), The E-Business Handbook, CRC Press LLC, Boca Raton, FL (2002)

P.M.A. Van Bilsen Care for the elderly. An Exploration of Perceived Needs, Demands and Service Use Maastricht University, Maastricht (2008)

C. Van Campen, I.B. Woittiez Client demands and the allocation of home care in the Netherlands A Multinomial Logit Model of Client Types, Care Needs and Referrals Health Policy, 64 (2) (2003), pp. 229-241

van der Lucht F., Polder, J.J. Van gezond naar beter. Kernrapport van de Volksgezondheid Toekomst Verkenning 2010. Bilthoven: RIVM,2010. 〈http://www.vtv2010.nl/〉

S.L. Vargo, R.F. Lusch Evolving to a new dominant logic for marketing Journal of Marketing, 68 (1) (2004), pp. 1-17

R. Verma An empirical analysis of management challenges in service factories, service hops, mass services and professional services International Journal of Service Industry Management, 11 (1) (2000), pp. 8-25

C. Voss Case management in operations research C. Karlsson (Ed.), Researching Operations Management, Routledge, New York, NY (2009)

C. Voss, A.V. Roth, R.B. Chase Experience, service operations strategy, and services as destinations: Foundations and exploratory investigation Production and Operations Management, 17 (3) (2008), pp. 247-266 
Blok, C. de, Meijboom, B., Luijkx, K., Schols, J. The human dimension of modular care provision: opportunities for personalization and customization. International Journal of Production Economics: 2013, 142(1), 16-26

C. Voss, N. Tsikriktsis, M. Frohlich Case research in operations management International Journal of Operations and Production Management, 22 (2) (2002), pp. 195-219

C.A. Voss, J. Hsuan Service architecture and modularity Decision Sciences, 40 (3) (2009), pp. 541-569

T. Ware, T. Matosevic, B. Hardy, M. Knapp, J. Kendall, J. Forder Commissioning care services for older people in England: The view from care managers, users and carers Ageing \& Society, 23 (2003), pp. 411-428

U. Wemmerlov A taxonomy for service processes and its implications for system design International Journal of Service Industry Management, 1 (3) (1990), pp. 20-40 WHO Home-Based Long Term Care World Health Organization, Geneva (2000) , 2001

J. Wind, A. Rangaswamy Customerization: The next revolution in mass customization Journal of Interactive Marketing, 15 (1) (2001), pp. 13-32

R.K. Yin Applications of Case Study Research Sage Publications, Newbury Park (1993)

R.K. Yin Case Study Research (Third edn.)Sage Publications, Inc, Thousand Oaks (2003)

D. Zahay, A. Griffin Customer learning processes, strategy selection, and performance in business-to-business service firms Decision Sciences, 35 (2) (2004), pp. 169-203

V.A. Zeithaml, R.N. Bolton, J. Deighton, T.L. Keiningham, K.N. Lemon, J.A. Petersen Forward-looking focus: Can firms have adaptive foresight? Journal of Service Research, 9

(2) (2006), pp. 168-183

\section{TABLES AND FIGURES}

Table 1

Customization and personalization compared and contrasted.

\begin{tabular}{|c|c|c|}
\hline & Customization & Personalization \\
\hline Definition & $\begin{array}{l}\text { The configuration of products (goods and services) that meets } \\
\text { customers' individual needs }\end{array}$ & $\begin{array}{l}\text { The adaptation of employee interpersonal behavior such that it } \\
\text { suits a particular customer's preferences }\end{array}$ \\
\hline $\begin{array}{r}\text { Main field of } \\
\text { application }\end{array}$ & Product design and operations management & Service marketing and management \\
\hline Focus & $\begin{array}{l}\text { The contents of the product (good or service) to be delivered to the } \\
\text { customer }\end{array}$ & The way in which the service is delivered to the customer \\
\hline Outcome & Product tuned to individual requirements & Interactions tuned to individual requirements \\
\hline $\begin{array}{l}\text { Position in care/ } \\
\text { service life cycle }\end{array}$ & Mainly at the start of the life cycle, when products are configured & Throughout the life cycle at all point of customer contact \\
\hline How to achieve & $\begin{array}{l}\text { Through modularity: } \\
\text { - Choosing components from a menu } \\
\text { - Adapting a product prototype }\end{array}$ & $\begin{array}{l}\text { Through various ways of adapting interpersonal interactions: } \\
\text { - Pro forma personalization } \\
\text { - Attentive personalization }\end{array}$ \\
\hline
\end{tabular}


Blok, C. de, Meijboom, B., Luijkx, K., Schols, J. The human dimension of modular care provision: opportunities for personalization and customization. International Journal of Production Economics: 2013, 142(1), 16-26

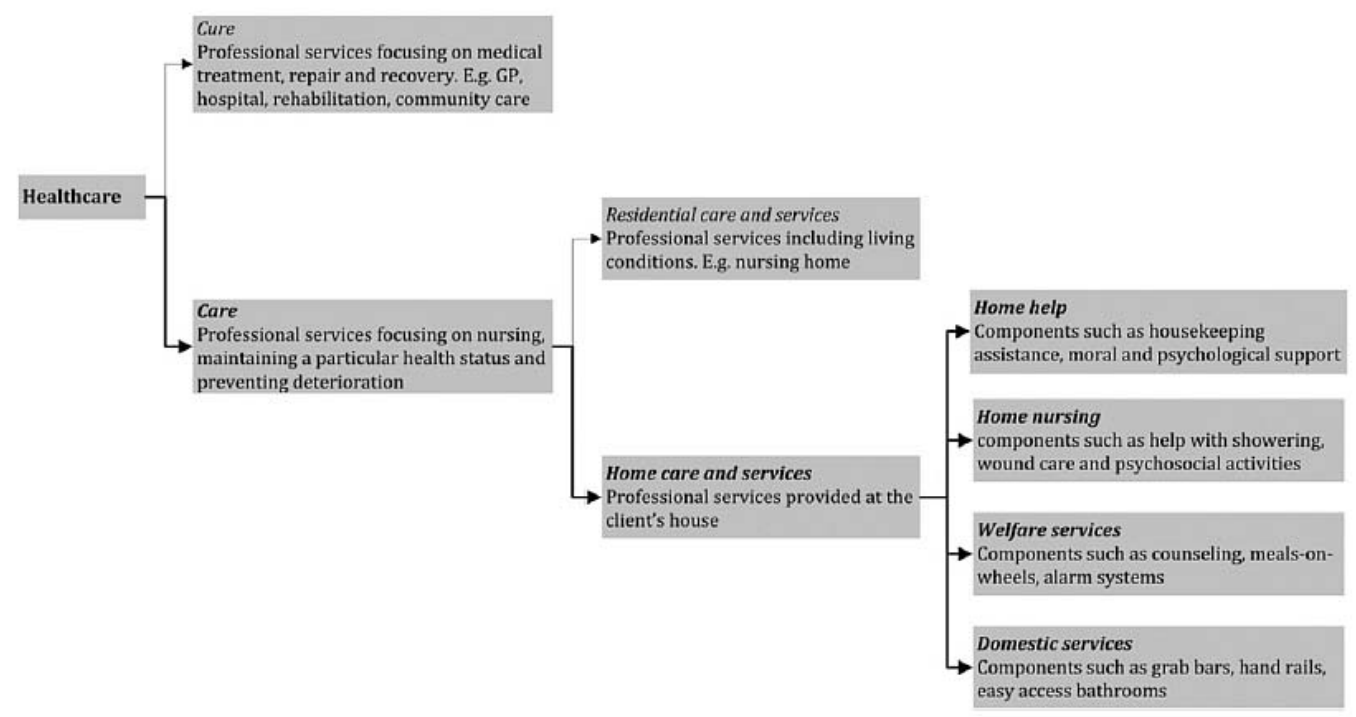

Fig. 1. Healthcare sector and focus of the current research (i.e., boxes and arrows printed bold).

Table 2

Sample of case organizations.

\begin{tabular}{|c|c|c|c|c|}
\hline & Case K & Case $\mathbf{R}$ & Case $\mathbf{T}$ & Case V \\
\hline Number of clients in 2009 & 20,317 & 4000 & 20,317 & 28,746 \\
\hline $\begin{array}{l}\text { Number of service workers in } \\
2009\end{array}$ & 6,193 & 2300 & 6,193 & 8,600 \\
\hline Turnover in 2009 & $€ 187 \mathrm{mln}$ & $€ 88 \mathrm{mln}$ & $€ 187 \mathrm{mln}$ & $€ 280 \mathrm{mln}$ \\
\hline Urbanization of working area & $\begin{array}{l}\text { Countryside }(23,000 \\
\text { inhabitants) }\end{array}$ & $\begin{array}{l}\text { Small city }(77,500 \\
\text { inhabitants) }\end{array}$ & $\begin{array}{l}\text { Large city (202.000 } \\
\text { inhabitants) }\end{array}$ & $\begin{array}{l}\text { Two small cities ( } 92,000 \text { and } 54,000 \\
\text { inhabitants) }\end{array}$ \\
\hline History in & $\begin{array}{l}\text { Home care and residential } \\
\text { care }\end{array}$ & Residential care & Home care & Home care and residential care \\
\hline Main client population & \multicolumn{4}{|l|}{ Elder clients } \\
\hline Service range & \multicolumn{4}{|c|}{$\begin{array}{l}\text { Home care, home nursing, welfare, domestic services, leisure activities, social support, safety services, comfort services, residential care } \\
\text { and services }\end{array}$} \\
\hline Product and process stability & \multicolumn{4}{|c|}{ Certified with care related ISO-9000 (HKZ-certificate) } \\
\hline
\end{tabular}

Care process over
time $\longrightarrow$ A-priori specification $\quad \longrightarrow$ On-the-job adaptation

Menu components

Customization

Package prototype
Change component dimensions

Pro-forma personalization

Personalization

Attentive personalization: adapt interaction and communication

Attentive personalization: matching personality

Fig. 2. Customization and personalization along the care process. 